\title{
Riego deficitario en granado. Relaciones hídricas y crecimiento del fruto
}

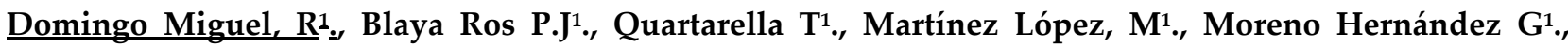 \\ Giménez Gallego, J1'. Torres Sánchez, R¹.
}

1Universidad Politécnica de Cartagena. rafael.domingo@upct.es; pedro.blaya@upct.es; t.quartarella@studenti.uniba.it; marianoupct@gmail.com; gmorenohdez6@gmail.com; jaime.gimenez@upct.es; roque.torres@upct.es

Resumen: con la convicción de que los agrosistemas mediterráneos tienen que afrontar la necesidad de convivir con la escasez de agua, y que resulta muy difícil, si no imposible, poder satisfacer las necesidades máximas de agua de la mayoría de los cultivos; diseñamos un ensayo de riego deficitario (RD) en granado "Wonderful" bajo malla, para estudiar las relaciones hídricas y poder ajustar los volúmenes de riego y elegir la estrategia de manejo más adecuada bajo las condiciones de cultivo.

El ensayo se inició en 2021 en una plantación de granado "Wonderful" bajo malla de sombreo 30\%, perteneciente al Grupo Paloma (Mazarrón). Los árboles formados en vaso abierto y a marco de $5 \mathrm{~m} \mathrm{x}$ $3,5 \mathrm{~m}$, presentaban un diámetro de tronco entre $11,5-12,2 \mathrm{~cm}$ y un porcentaje de área sombreada del $43 \%$. El riego por goteo constó de un único lateral por hilera de árboles y 3 emisores autocompensantes de $4 \mathrm{~L} / \mathrm{h}$ por árbol. El agua de riego, de pozo, presentó un $\mathrm{pH}$ de $7,9, \mathrm{CE}_{25^{\circ} \mathrm{C}}$ de 2,6 $\mathrm{dS} \mathrm{m}^{-1}$ y una concentración de cloruros y sodio de 10,9 y 11,9 meq L-1, respectivamente. Los tratamientos en curso son: i) control (CTL) con riego al 115\% ETc, ii) riego deficitario sostenido (RD) regado al 75\% CTL, iii) riego deficitario controlado (RDC) con riego al 40 - 100 - 70\% CTL durante las fases: floración, cuajado y crecimiento inicial del fruto (junio) - tramo II de la fase de rápido crecimiento del fruto - fase final del período de crecimiento y maduración del fruto, y iv) finca (FCA) regado de acuerdo al criterio del técnico de la empresa. El diseño experimental es de bloques al azar y tres repeticiones por tratamiento.

Los resultados de la campaña de riego actual, periodo marzo-primera semana de julio, indican un ahorro de agua respecto a CTL del 20; 25 y 53\% para FCA, RD y RDC, respectivamente. La evolución del fruto y diámetro medio es similar en los cuatro tratamientos ( $\mathrm{d}=62 \mathrm{~mm}$-DDA 187). Aunque no hubo diferencias de potencial matricial del agua en el suelo $\left(\Psi_{\mathrm{m}}\right)$, debido a su alta variabilidad, si se dieron de potencial de tallo a mediodía $\left(\Psi_{t}\right)$ para RDC desde principios de junio hasta el cambio de riego al 100\% de CTL, primera semana de julio. De igual modo que en $\Psi_{\mathrm{m}}$, no se observaron diferencias de conductancia estomática $\left(\mathrm{g}_{\mathrm{s}}\right)$ a excepción de los días previos al cambio de riego en RDC. Aunque son resultados preliminares y se requiere de los resultados que deriven de los años posteriores, éstos sugieren una buena adaptabilidad del granado al déficit hídrico, al mantener una evolución y tamaño de fruto similar, el cual es una de las principales características de calidad de la granada a nivel comercial. Dada la excelente aceptación de la variedad Wonderful para exportación, tanto el volumen de riego actualmente aplicado como las características principales del fruto son resultados alentadores.

Palabras clave: potencial de tallo a mediodía; intercambio gaseoso; dinámica de crecimiento, Punica granatum L. 